\title{
Inverting a non-major's biology class: Using video lectures, online resources, and a student response system to facilitate deeper learning
}

\begin{abstract}
Jayson E. Lloyd ${ }^{1}$ and William C. Ebener ${ }^{2}$
Abstract: Instructors hypothesized that inverting/flipping a non-major's biology class by using pre-recorded video lectures, online resources, and a student response system (iClicker), would facilitate deeper learning. Following an inverted classroom format, students viewed lecture videos and completed online activities prior to face-to-face meetings with instructors. During face-to-face (traditional "lecture") time, instructors tested student knowledge and guided students in group learning activities. Using a quasi-experimental design, researchers compared student performance on a comprehensive final exam with student performance from a previous semester. An independent sample t test indicated that students engaged in the inverted instructional model $(N=73, M=$ $74.49, S D=12.54)$ performed better than students engaged in a traditional model of instruction $(N=76, M=70.32, S D=12.19), t(147)=2.06, p=0.02$ on the same comprehensive final exam. The effect size for this analysis $(d=0.33)$ represents a small effect according to Cohen (1988). Researchers also performed a chi-square test of goodness-of-fit to determine if final lecture grade distributions from the inverted model differed from the traditional model. Final lecture grade distributions from the inverted model were significantly different, $X^{2}$ $(5, N=102)=30.22, p<.05$, showing a decrease of " $F$ " and "Withdraw" grades for the inverted model.
\end{abstract}

Keywords: Pedagogy, Inverted, Flipped, Higher Education

The inverted or flipped classroom is a current trend in higher education and has been implemented in various forms from kindergarten to college (Thompson, 2011). Walvoord and Poole (1998) noted that the traditional lecture has historically provided students with their first exposure to material. Flipping this procedure, Walvoord and Poole (1998) argued that students should experience first exposure on their own time outside of the classroom. Lage and Platt (2000) proposed that technology would make this easier and thereby free up traditional lecture time to engage in rich learning experiences. Bowen (2011) confirmed Lage's and Platt's vision and argues that modern technology indeed provides many ways to invert pedagogy and thereby enrich students learning experiences in the classroom.

Proponents of the inverted/flipped classroom argue that educational institutions must develop richer learning experiences for students and that these experiences should inspire students to learn rather than simply provide students with knowledge (Short \& Martin, 2011). These proponents cite research indicating that the traditional lecture experienced by most students during the first three semesters of college have little impact on their ability to write, think critically and engage in complex reasoning. In a study of 2,300 students at 24 institutions,

\footnotetext{
${ }^{1}$ Biology Chair, Biology Department, College of Southern Idaho, jlloyd@csi.edu

${ }^{2}$ Biology Instructor, Biology Department, College of Southern Idaho, bebener@csi.edu
} 
Arum and Roksa (2011) demonstrated that 45\% of the students studied exhibited no statistically significant improvement in the skills listed above. Because researchers have shown that student engagement and faculty-student interactions matter the most in student learning, inverted/flipped proponents feel their pedagogy can improve student learning by promoting these conditions and interactions (Astin, 1993).

Bishop and Verleger (2013) reviewed the current state of research concerning the inverted classroom. Despite a relatively large amount of published research concerning the inverted classroom, there is limited scholarly research on the effectiveness of the inverted strategy. The existing scholarly studies report that students' perceptions of the flipped classroom are generally positive. There is also anecdotal evidence suggesting that the inverted/flipped classroom improves students' learning when compared to the traditional classroom. However, there is very little objective research concerning student learning outcomes (Bishop \& Verleger, 2013). The goal of this study was to help address the lack of objective measurements by comparing the performance of students taught traditionally and in an inverted classroom using the same objective metrics.

Instructors of the Hunan Structure and Function course at the College of Southern Idaho hypothesized that the inverted instructional model held promise in facilitating deeper learning while at the same time addressing difficulties identified in the current course. Instructors teaching this course have historically struggled with student apathy, poor attendance, lack of student preparation, a wide range of student abilities, and poor student success. Researchers have documented that problems such as these are commonly associated with traditional lecture strategies (Ramsden, 2003).

\section{Method}

\section{Participants}

Students enrolled in Human Structure and Function courses at the College of Southern Idaho (CSI) participated in this study. All students enrolled in the Spring 2013 Semester experienced an inverted pedagogical model while all students enrolled in the Fall of 2012 experienced traditional lecture pedagogy. Students take the Human Structure and Function course in order to prepare for various professional technical health care careers such as certified nursing assistant, dental assistant, and medical assistant. Human Structure and Function is a four credit course taught over 16 weeks. The course does not meet general education requirements and is not designed for transferability. Students enrolling in Human Structure and Function take a three credit lecture section and a one credit laboratory section concurrently.

Historically, Human Structure and Function has attracted a diverse population of students. These students often display poor study skills and struggle with demonstrating their knowledge and understanding. Human Structure and Function instructors report that student apathy, low student attendance, minimal student engagement, and dismal success rates are quite common in their courses. Failure rate, as indicated by final grades, show that Human Structure and Function students typically fail (loosely defined here as earning an " $F$ ") $26 \%$ of the time. Moreover, over $27 \%$ of the students withdraw from the class sometime during the semester.

\section{Research Design}


Researchers implemented a quasi-experimental design and compared the comprehensive final exam scores of students taught with the inverted pedagogy model in the Spring Semester of 2013 to those taught in a traditional lecture model during the Fall Semester of 2012. All students registered in Human Structure and Function at CSI for the Fall 2012 Semester experienced learning in a traditional lecture environment. Those students registered for the same class during the Spring 2013 Semester experienced the inverted classroom environment. The researchers used an identical comprehensive multiple choice exam to test all students at the end of both semesters.

Human Structure and Function students enroll in a lecture section as well as a laboratory section. Typically, the lecture sections hold up to 60 students while the laboratory sections hold up to 27 students. During the Fall 2012 Semester, two full-time faculty and two part-time faculty covered the three lecture sections and six laboratory sections offered at the college. During the Spring 2013 Semester, three full-time professors and two part-time instructors covered the three lecture sections and six laboratory sections offered at the college. Full-time faculty maintained responsibility for the lecture sections and a handful of laboratory sections, while the part-time faculty only taught laboratory sections during both semesters. All faculty teaching lecture sections during the Spring 2013 Semester employed the inverted model. The laboratory actives and teaching style in both the Fall 2012 and Spring 2013 Semesters remained unchanged. In order to minimize confounding variables and because the flipped design was implemented in the lecture sections, researchers chose to compare scores from the lecture comprehensive final exam given each semester. Researchers also compared final lecture grade distributions between the inverted and traditional models. Such a comparison allowed researchers to obtain a view of student performance in the lecture and avoid the direct influence of laboratory scores as a confounding variable.

\section{Measures}

Scores for a student's final exam performance were tallied using an Acu-Scan fill-in bubble form from the comprehensive, multiple choice final exam. A student's comprehensive final exam score represented the percentage of questions answered correctly on a 100 question, multiple choice, comprehensive test.

Students' final lecture grades were measured as A, B, C, D, F, or W grades. A student's lecture course grade represented the students' overall performance in only the lecture section of the class. The $\mathrm{W}$ grade was assigned to students who officially withdrew from the class. Students may officially withdraw from the course through the first $75 \%$ of the semester.

Researchers also captured data concerning the amount of time spent during the face-toface class for various activities. An observer measured time spent on (a) testing, (b) business, (c) lecturing, and (d) group activities using a stopwatch during each class. Researchers defined testing time as the time spent on the homework accountability exams; business time included time the instructor spent making announcements and organizing the class; lecture time included any time the instructor delivered information about course content; group activities included the time students worked on responding to questions and evaluating each others' responses.

\section{Procedure}

Journal of Teaching and Learning with Technology, Vol. 3, No. 2, December 2014. 
Based loosely on Mazur's (1996) model of inverted instruction, faculty for Human Structure and Function implemented an inverted pedagogy by posting online videos and activities for students to complete prior to each face-to-face meeting. These actives were assigned as homework for students and were delivered to students via the campus course management system (Blackboard). Each homework assignment usually consisted of approximately 30 minutes of video, 5-20 pages of reading from an assigned textbook, and voluntary online activity such as self-grading quizzes. The video lectures were compiled from existing lectures created by various teachers found on YouTube and video clips created by the instructors of this study using Camtasia. Other online activities, such as self-grading quizzes, online flashcards, and labeling exercises were accessed through the textbook publisher's online resources and a variety of free websites such as http://highered.mheducation.com/sites/0072919280/student_view0/index.html.

The instructor encouraged students to complete the homework by testing the students on the content of the video lectures at the beginning of each face-to-face meeting (traditional lecture time). These homework accountability quizzes consisted of approximately 10 questions and polled students on their understanding of the basic concepts presented in the video lectures. The instructor implemented these homework accountability quizzes by using the iClicker Student Response System which allowed students to electronically answer questions with their personal iClicker remotes. iClicker software allowed the lecturer to capture instant results for each question and record individual student scores electronically. Because the iClicker system implemented at CSI only allowed for multiple choice voting, all homework accountability quizzes were structured as multiple choice questions.

After the homework accountability quizzes, the instructor would randomly establish groups composed of three to five students. Students were then provided with time to discuss questions they had generated from their experience with the homework and the homework accountability quiz. Students wrote questions they wished addressed on note cards which the instructor collected. Having collected the students' questions, the instructor organized the questions into categories to facilitate discussion. On-topic questions, questions that dealt with stated learning objectives, were addressed first. Off-topic questions, questions that strayed from the learning objectives were recognized by the instructor as being off-topic and students interested in those questions were encouraged to meet with the instructor outside of official class time.

In order to address student questions, the instructor presented the question to the class and asked for a group to volunteer to respond to the posed question. Volunteers were encouraged to participate by awarding participation points. These points were awarded and tracked by using the iClicker Response System. The group chosen to respond presented its response to the class during which time the instructor took notes on the board in front of the entire class, thereby documenting the response of the group.

Once the group had presented its response and felt that the instructor's notes accurately reflected the response, the instructor asked the class to evaluate the provided response. Each student was expected to analyze and then vote on the response using his or her student iClicker system. Because the iClicker system utilized at CSI only allows for multiple choice feedback, students had to choose whether the group's response was (a) correct, (b) partially correct but something important was missing, (c) partially correct but something presented was incorrect, (d) 
partially correct but something important was missing and something was incorrect, or (e) incorrect.

After each student voted, the instructor provided the correct analysis. Students that correctly judged the presentation earned points. Those disagreeing with the instructor's analysis were provided with an opportunity to defend their judgment. If the instructor deemed a student's defense logical and valid, he awarded points to the students who voted accordingly.

If no group volunteered, the instructor would allow the class approximately five minutes to attempt to find a defensible response. During this time, the instructor encouraged students to search the internet as well as their text book or any other source of information that might prove useful. The first group ready to present its response after researching was allowed the opportunity to present and earn participation points.

This process continued until the end of the class period. If the class addressed all student

\section{Lecture Grade Distribution Class X}

$50.00 \%$

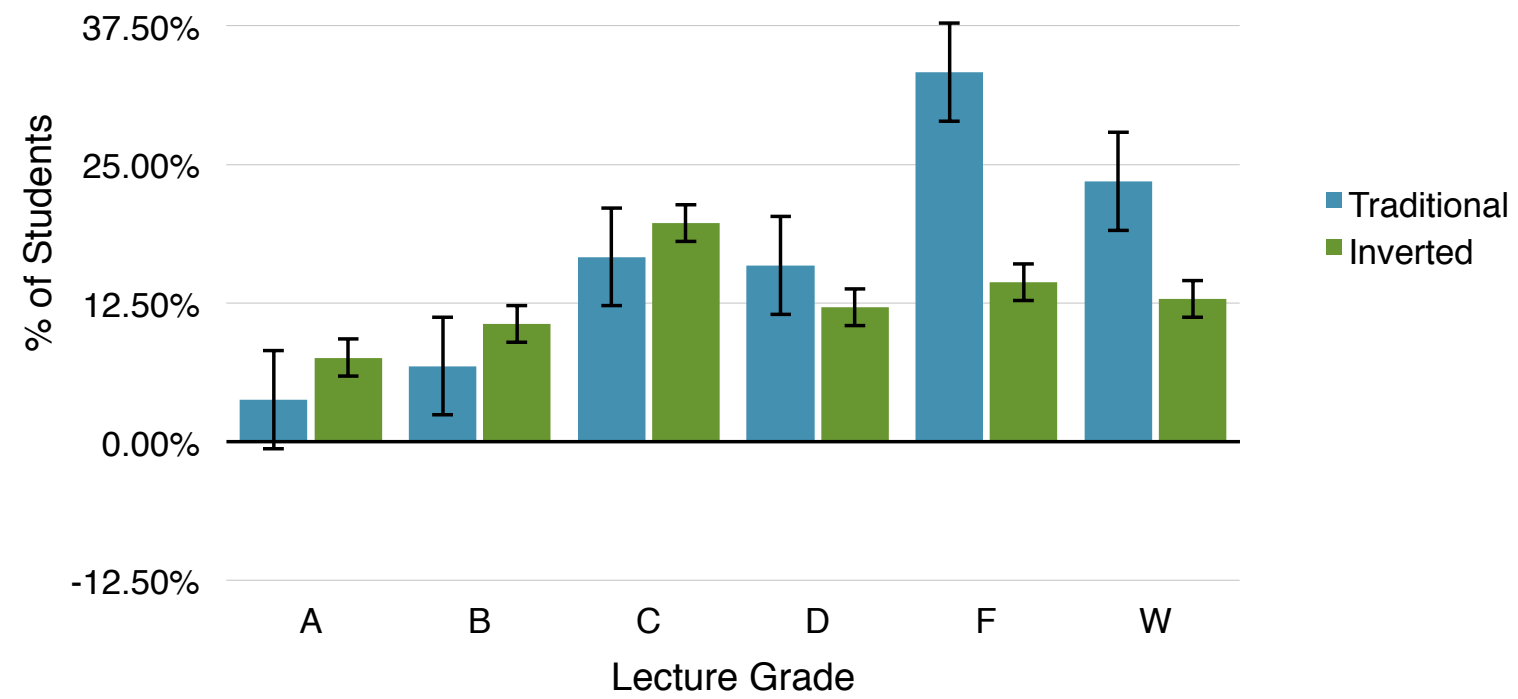

Figure 1: Student grade distributions (\%) for inverted verses traditional biology classes ( $\mathrm{n}=102)$. Note: Students who officially dropped the course receive a W grade on their transcripts.

generated questions, the instructor spent the remaining class time testing the students on the material using the student response system. This only happened once during the semester.

\section{Results}

An independent group $\mathrm{t}$ test indicated that there was significant difference in the comprehensive final exam test scores between the inverted pedagogy $(N=73, M=74.49, S D=$ $12.54)$ and the traditional lecture pedagogy $(N=76, M=70.32, S D=12.19), t(147)=-2.06, p=$ 0.02 . The effect size for this analysis $(d=0.33)$ represents a small effect according to Cohen (1988). A chi-squared test of goodness-of-fit determined that the student lecture grade 
distribution from the inverted model differed significantly from the traditional model, $X^{2}(5$, $N=102)=32.22, p<.05$. As seen in Figure 1 , fewer students earned $\mathrm{F}$ and $\mathrm{W}$ grades in the inverted model.

Researchers also found that instructors using the inverted pedagogy allocated time very differently than in a traditional lecture. Survey data from Watts and Becker (2008) indicate that instructors spend $83 \%$ of class time lecturing in undergraduate classes. Instructors using the inverted model in this study allocated only $15 \%$ of the face-to-face time for lecturing, while $52 \%$ of the time was used for interactive/group activities, $25 \%$ of the time for testing, and $8 \%$ of the time for administrative task (establishing groups, making announcements, organizing questions). Additionally, tracking data demonstrated that on average $71 \%$ of the students participated in the online learning activities prior to attending the face-to-face lecture.

\section{Discussion}

Overall, instructors were pleased with the results of the inverted pedagogy. After having implemented the inverted class design, all instructors observed significant improvements in student performance and learning outcomes. Because of this, the instructors have continued to implement inverted pedagogy in their classes. Despite a small measured effect size on the final exam scores, instructors noted that students attending inverted classrooms came away from their classes with greater gains in personal accountability, improved study skills, greater willingness to take personal responsibility for their learning, increased ability to work in groups, increased critical thinking skills, and improved ability to articulate their thoughts. Unfortunately, objectively documenting gains in these areas proves difficult. Yet more and more college instructors choose to adopt the inverted model because of such perceived gains (Arnaud, 2013).

Instructors also noted that students withdrew from the inverted classroom within the first three weeks, while those in the traditional classroom withdrew much later in the semester. Moreover, students experiencing the inverted classroom attended class consistently throughout the entire semester whereas student attendance in the traditional lecture classes was generally sporadic. Lack of attendance data from Fall 2012 prevented actual comparison. However, the difference in student grade distributions between the inverted and the traditional model indicates that the inverted model created an environment in which fewer students earned $\mathrm{F}$ and $\mathrm{W}$ grades. The significant difference in the number of students earning $\mathrm{F}$ and $\mathrm{W}$ grades in the inverted model, helps demonstrates the value of the inverted model in addressing poor student performance, poor attendance, student apathy and student persistence in the course. The researchers hypothesize that the inverted model is largely successful because it provides a cogent method to communicate and train students in the skills and habits necessary for individual learning. Others have noted that inverted models allow teachers more time to monitor student performance and provide immediate feedback to individuals and groups of students (Fulton, 2012; Herreid \& Schiller, 2013). Future research should be conducted to document whether the inverted pedagogy influences students as the instructors of this study observed.

Conducting this experiment proved to be difficult for the instructors because of the new skills required to manage an inverted classroom. Stayer (2012) noted that instructors often struggle with balancing active learning and lecture activities in the inverted environment. Moreover, other researchers have documented that instructors are often not prepared to apply the inverted pedagogy because of the changing roles and responsible associated with studentcentered learning (Brush \& Saye, 2000; Hannafin et al., 1997). Instructors in this study described 
the switch from lecturing to managing an inverted classroom as traumatic. Instructors were required to facilitate student discussion and interaction in real time instead of deliver predefined information to the class. Because of this, instructors often described their new role more as a mentor or a referee. The referee analogy is apt because instructors felt that an inverted classroom was similar to a sporting event. Students come to the inverted class to "play" while the instructor functions as a referee. As the players, the students perform, deliver the information, think critically, and articulate what is important and meaningful. As the referee, it is the instructor's responsibility to judge the students' performance, to keep the students "in bounds" and on topic, and to provide guidance and feedback concerning student performance. After working with the inverted model, one instructor noted that the best classes, just like the best sporting events, always focused on the players (students) not the referees.

When describing the traditional verses the inverted lecture experience, instructors built on the sports analogy. In the traditional lecture, if the sport was basketball, the instructor explains how to shoot free-throws and then shoots the free-throws while the students observe. In the inverted model, students have already been instructed and watched the lecturer's performance online; they come to class to actually shoot free-throws themselves.

Instructors found it difficult to avoid lecturing in the inverted model, especially considering that students often demanded and expected instructors to lecture. The lecturers felt that students advocated for the traditional model because they could avoid accountability and work. Students find it easy to simply observe, (or text, or check Facebook, or daydream) while the instructor lectures. Additionally, instructors felt comfortable lecturing, in so much that instructors actually described their desire to lecture as an addiction. Instructors found that lecturing made them feel accomplished and effective as compared to the frustration of listening to students answer questions incorrectly, argue over concepts, and sometimes sit in silence unwilling to address a question. Lecturing also helped free instructors from feeling culpable for student failure. Instructors in this study described that when students failed in the traditional model, they could excuse themselves from that failure by explaining how they had covered the material in lecture. It was therefore the student's fault that he or she had not mastered the concept(s). The inverted model created an atmosphere that removed much of that justification. Face-to-face time became a time where students demonstrated their understanding, which often times became a display of ignorance. Such displays created uncomfortable atmospheres for both student and instructor. However, instructors from this experiment felt that these uncomfortable experiences provided valuable insight and motivation to both student and instructor. They functioned as wake up calls to both parties and allowed instructors and students to adjust behaviors early to promote success.

Because of the challenge in managing an inverted classroom, the instructors found peer support very helpful. Often times, instructors found the presence of the observer, who was measuring time allocation, very helpful in maintaining the inverted structure. Being able to work as a team allowed the two instructors to minimize their "lecture addiction." Instructors also found that the inverted model worked better when allowed to meet for longer periods of time with the students. For instance, the class meeting two days per week for one hour and 20 minutes seemed to provide a better format for the inverted process than classes meeting three days per week for 50 minutes.

In conclusion, the modest increase in student performance on the comprehensive final exam along with the significant decrease in $\mathrm{F}$ and $\mathrm{W}$ grades demonstrated by students in the inverted model, provide objective support that corroborates the existing anecdotal evidence 
concerning the efficacy of the inverted/flipped pedagogy. Additionally, the subjective observations of instructors noting improvement in student participation, groups skills, critical thinking, and personal responsibility for learning during this study support the current research that demonstrates the value of the inverted/flipped classroom. Although a challenge to implement because of the new skills required from instructors and the work necessary to restructure a class, the inverted model proves especially effective at decreasing the numbers of students that fail (earn F or W grades).

\section{References}

Arnaud, C. H. (2013). Flipping chemistry classrooms: Professors shift lectures online to free up class time for more effective learning activities. Chemical and Engineering News, 91, 41-43.

Arum, R., \& Roksa, J. (2011). Academically adrift: Limited learning on college campuses. Chicago: University of Chicago Press.

Astin, A.W. (1993). What matters in college: Four critical years revisited. San Francisco: Jossey-Bass.

Bishop, J. L., \& Verleger, M. A. (2013, June). The flipped classroom: A survey of the research. In ASEE National Conference Proceedings, Atlanta, GA.

Brush, T., \& Saye, J. (2000). Implementation and evaluation of a student-centered learning unit: A case study. Educational Technology Research and Development, 48(3), 79-100. doi: 10.1007/BF02319859

Cohen, J. (1988). Statistical power analysis for the behavioral sciences (2nd ed.). Hillsdale, NJ: Lawrence Earlbaum Associates.

Fulton, K. (2012). Upside down and inside out: Flip your classroom to improve student learning. Learning \& Leading with Technology, 39(8), 12-17.

Hannafin, M., Hill, J., \& Land, S. (1997). Student-centered learning and interactive multimedia: Status, issues, and implication. Contemporary Education, 68(2), 94-99.

Herreid, C., \& Schiller, N. (2013). Case studies and the flipped classroom. Journal of College Science Teaching, 42(5), 62.

Lage, M.J., \& Platt, G. (2000). The internet and the inverted classroom. Journal of Economic Education, (31)11. doi: 10.1080/00220480009596756

Mazur, E. (1996). Peer Instruction: A user's manual. Upper Saddle River, JH: Prentice Hall. Ramsden, P. (2003). Learning to teach in Higher Education. UK: Routledge. 
Short, F., \& Martin, J. (2011). Presentation vs. performance: Effects of lecturing style in higher education on student preference and student learning. Psychology Teaching Review. 17(2), 7182.

Thompson, C. (2011). How the Khan academy is changing the rules of education. Wired Magazine. Retrieved from http://www.wired.com/magazine/2011/07/ff_khan/all/1.

Walvoord, B.E., \& Poole, K.J. (1998). Effective grading. San Francisco: Jossey-Bass.

Watts, M., \& Becker, W.E. (2008). A little more chalk and talk: Results from a third national survey of teaching methods in undergraduate economics courses. Journal of Economic Education. 39(3), 273-286. doi: 10.3200/JECE.39.3.273-286 